\title{
Clinical Characteristics, Genetic Findings and Arrhythmic Outcomes of Patients with Catecholaminergic Polymorphic Ventricular Tachycardia from China
}

\author{
Sharen Lee ${ }^{1,+}$, Justin Leung ${ }^{1,+}$, Jiandong Zhou MSc PhD ${ }^{2}$, Kamalan Jeevaratnam PhD ${ }^{3}$, Ishan Lakhani ${ }^{1}$, Danny \\ Radford BSc ${ }^{4}$, Emma Coakley-Youngs PhD ${ }^{4}$, Levent Pay MD 5, Göksel Çinier MD 5, Meltem Altinsoy MD 6 , \\ Elham Mahmoudi MD 7, Paweł T. Matusik, MD PhD FEHRA 8, George Bazoukis MD PhD FESC 9,10, Sebastian \\ Garcia-Zamora MD ${ }^{11}$, Shaoying Zeng MD ${ }^{12}$, Ziliang Chen MD ${ }^{13}$, Yunlong Xia MD PhD FESC FACC ${ }^{14}$, Tong Liu \\ MD PhD FESC 13,", Gary Tse MD PhD FRCPCH FRCP 1,3,4,13,14*
}

\footnotetext{
${ }^{1}$ Cardiac Electrophysiology Unit, Cardiovascular Analytics Group, Hong Kong, China-UK Collaboration

2 School of Data Science, City University of Hong Kong, Hong Kong, China

${ }^{3}$ Faculty of Health and Medical Sciences, University of Surrey, Guildford, UK

${ }^{4}$ Kent and Medway Medical School, Canterbury, Kent, United Kingdom

${ }^{5}$ Department of Cardiology, Dr Siyami Ersek Hospital Thoracic and Cardiovascular Surgery Training and Research Hospital, Istanbul, Turkey

${ }^{6}$ Department of Cardiology, University of Health Sciences, Diskapi Yildirim Beyazit Training and Research Hospital, Ankara, Turkey

${ }^{7}$ Universal Scientific Education and Research Network (USERN), Tehran University of Medical Sciences,

Tehran, Iran

${ }^{8}$ Department of Electrocardiology, Institute of Cardiology, Jagiellonian University Medical College, John Paul II Hospital, Kraków, Poland

${ }^{9}$ Department of Cardiology, Larnaca General Hospital, Larnaca, Cyprus

${ }^{10}$ University of Nicosia, Medical School, Nicosia, Cyprus

${ }^{11}$ Department of Cardiology and Cardiac Intensive Care Unit, Delta Clinic. Rosario, Argentina

${ }^{12}$ Department of Pediatric Cardiology, Guangdong Cardiovascular Institute, Guangdong Provincial Key Laboratory of South China Structural Heart Disease, Guangdong Provincial People's Hospital, Guangdong Academy of Medical Sciences, Guangzhou 510080, China

${ }^{13}$ Tianjin Key Laboratory of Ionic-Molecular Function of Cardiovascular Disease, Department of Cardiology, Tianjin Institute of Cardiology, Second Hospital of Tianjin Medical University, Tianjin 300211, China ${ }^{14}$ Department of Cardiology, First Affiliated Hospital of Dalian Medical University, Dalian, Liaoning, China

† joint first authors

* Correspondence to: Prof. Tong Liu (liutongdoc@126.com) or Prof._Gary Tse (g.tse@surrey.ac.uk / garytse@tmu.edu.cn / gary.tse@kmms.ac.uk)
}

\begin{abstract}
Introduction: Catecholaminergic polymorphic ventricular tachycardia (CPVT) is a rare cardiac ion channelopathy. The aim of this study is to examine the clinical characteristics, genetic basis and arrhythmic outcomes of CPVT patients from China. Methods: PubMed and MedRxiv were systematically searched for case reports or case series reporting on CPVT patients from China. Clinical characteristics, genetic findings and primary outcome of spontaneous ventricular tachycardia/ventricular fibrillation (VT/VF) were analyzed. Results: A total of 56 (median presentation age $=9$ [6-13] years old) patients were included. All patients except for one presented at or before 19 years of age. Fifty-three patients $(94.6 \%)$ were initially symptomatic. PVCs were present in 40 out of 45 patients (88.9\%) and VT in 51 out of 56 patients (91.1\%). Genetic tests were performed in 50 patients $(89.3 \%)$ with a yield of $76.8 \%$. RyR2, CASQ2 and TERCL mutations were found in 32 (57.1\%), 11 $(19.6 \%)$ and one $(0.02 \%)$ patients, respectively. Fifty patients were treated with beta-blockers, eight patients received flecainide, four patients received amiodarone, two received verapamil and one received propafenone. Sympathectomy $(n=10)$ and implantable-cardioverter defibrillator implantation $(n=7)$ were performed. On follow-up, 17 patients developed incident VT/VF. Conclusion: This is the first systemic review and metaanalysis of CPVT patients from China. Most patients had symptoms on initial presentation, and around a third had VT as the presenting complaint. RyR2 mutation accounts for more than half of the CPVT cases, followed by CASQ2 and TERCL mutations. Some of these mutations have not been hitherto reported outside of China. Most patients received $\beta$-blocker therapy. Around $18 \%$ had sympathectomy and $13 \%$ had ICDs implanted.
\end{abstract}




\section{Introduction}

Cardiac ion channelopathies predispose to the development of spontaneous ventricular tachycardia/ fibrillation (VT/VF) and sudden cardiac death (SCD) [1-6]. Of these, catecholaminergic polymorphic ventricular tachycardia (CPVT) is a less prevalent condition compared to Brugada syndrome (BrS) in Asia [7, 8]. It is typically caused by mutations in either the ryanodine receptor 2 (RyR2) [9] or the calsequestrin 2 (CASQ2) [10, 11], but mutations in other genes such as calmodulin (CALM) have been implicated [1214]. CPVT is usually precipitated by exercise or distress, which results in bidirectional VT, presenting in the first two decades of life [15]. Globally, population-based data on CPVT have mainly come from Western countries. The largest registry created by the Pediatric and Congenital Electrophysiology Society of the United States reported the characteristics of 237 patients [16, 17]. In another multi-national study including mainly patients from France, outcomes in 101 patients were reported [18], complementing smaller registry and case series studies by the same group [19, 20]. Another study reported specifically 21 CPVT patients caused by the CALM genes [12].

By contrast, data from Asia have been relatively sparse. A multi-centre Japanese registry of 78 patients found that $94 \%$ of the cases were sporadic with only $6 \%$ of the cases being familial [21]. In a national study from Japan, it was found that 30 gene mutation carriers were found for three genes in 50 probands [22]. Another Japanese reported on the findings of 29 patients [23]. However, to date, case descriptions from China have been limited to case series [11, 24-26] and there is no established registry nationally. Moreover, many of these reports are published in Chinese, and have limited accessibility to researchers beyond the country. Therefore, the aim of this study is to identify cases from a systematic search of the literature and synthesize evidence on clinical characteristics, genetic basis and arrhythmic outcomes of CPVT patients from China.

\section{Methods}

\subsection{Study Population}

PubMed and MedRxiv were systematically searched for case reports or case series that described CPVT patients from China, which allowed a primary synthesis of cases for analysis. Where overlapping cohorts were described, data were extracted from the publication with the largest cohort. Diagnosis of CPVT was established based on the exercise treadmill test, adrenaline challenge test, or genetic testing as defined by the individual papers. The individual cases were analyzed according to diagnostic criteria proposed by the 2013 Heart Rhythm Society (HRS)/ European Heart Rhythm Association (EHRA)/ Asia-Pacific Heart Rhythm Society (APHRS) expert consensus statement (Supplementary Table 1) [27]. All genetic mutations described in the studies were compared to those in the published literature [16, 28-31], in order to determine their possible pathogenicity and novelty.

\subsection{Data Extraction}

The following clinical data were extracted from the published studies: 1) sex, 2) age of presentation, 3) age of diagnosis, 4) family history of SCD or CPVT, 5) initial symptoms, initial presentation with 6) syncope, 7) palpitations, 8) chest pain or 8) seizures, the presence of 10) premature ventricular complexes (PVCs) or 11) ventricular tachycardia/ventricular fibrillation (VT/VF) detected on electrocardiography, Holter or exercise stress testing, 12) genetic testing, 13) methods of testing, 14) genetic results and 15) interpretation of the variants, 16) performance of 24-hours Holter study, exercise stress testing, electrophysiological study (EPS) and their respective results; 17) performance of echocardiogram and cardiac magnetic resonance imaging and results; 18) presence of bradycardic complications; 19) the presence of arrhythmias other than PVCs/VT/VF, 20) prescription of pharmacological agents and 21) implantation of implantable cardioverterdefibrillator (ICD). 


\subsection{Statistical Analysis}

Categorical variables were summarized as frequency (\%) and continuous variables were expressed as median (Q1-Q3). All statistical analysis was performed using Stata (Version: 16).

\section{Results}

Clinical characteristics, genetic findings and treatment

A systematic search of the PubMed and MedRvix databases yielded 1049 and 12 articles, respectively. After the exclusion of overlapping cohorts, a total of 56 unique cases from six cities by 11 studies were included [11, 25, 32-40]. Their clinical characteristics and test results are shown in Table 1. 21 patients fulfilled at least two criteria and 37 patients fulfilled one criterion of the $2013 \mathrm{HRS} / \mathrm{EHRA} / \mathrm{APHRS}$ expert consensus statement (Supplementary Table 1). Twenty 20 (35.7\%) patients were female and all patients were of Han Chinese origin. All patients except for one presented at or before 19 years of age. The median values (interquartile rate [IQR]) of the age of presentation and age of diagnosis were $9.0(6.4-12.9)$ and 10.1 (9.0-13.0) years old respectively, with a median delay of 12 (2-36) months. 53 patients (94.6\%) were initially symptomatic. PVCs were present in 40 out of 45 patients and VT in 51 out of 56 patients.

Genetic tests were performed in 50 patients $(89.3 \%)$. RyR2, CASQ2 and TERCL mutations were found in $32(57.1 \%), 11(19.6 \%)$ and $1(0.02 \%)$, respectively (Table 2$)$. The c.14861C>G mutation is novel and has not been described beyond China [25].

Pharmacological and non-pharmacological treatments for this cohort are summarized in Table 3 . Fifty patients were treated with $\beta$-blocker, eight patients received flecainide, four patients received amiodarone, two received verapamil and one received propafenone. Sympathectomy $(n=10)$ and ICD implantation $(n=7)$ were performed. On follow-up, 17 patients developed incident VT/VF.

Table 1. Baseline clinical and demographic characteristics of CPVT patients from China.

\begin{tabular}{cccc}
\hline Characteristic & $\begin{array}{c}\text { Median (Q1-Q3) / frequency } \\
(\mathbf{\%})\end{array}$ & Test & $\begin{array}{c}\text { Median (Q1-Q3) / } \\
\text { frequency (\%) }\end{array}$ \\
\hline Female & $20(35.7)$ & Echocardiogram & $35(62.5)$ \\
\hline $\begin{array}{c}\text { Presentation Age (years) } \\
\text { Diagnosis Age (years) }\end{array}$ & $9.0(6.4-12.9)$ & Abnormal echocardiogram & $4(11.4)$ \\
\hline $\begin{array}{c}\text { Presentation to Diagnosis } \\
\text { (months) }\end{array}$ & $12(9.0-13.0)$ & Cardiac MRI performed & $6(10.7)$ \\
\hline $\begin{array}{c}\text { Family History of } \\
\text { CPVT/SCD }\end{array}$ & $15(30.6)$ & Abnormal cardiac MRI & $0(0)$ \\
\hline Initially symptomatic & $53(98.1)$ & Genetic Test & $50(89.3)$ \\
\hline Initial syncope & $51(94.4)$ & Positive Genetic Test & $43(76.8)$ \\
\hline Initial VT/VF/SCD & $17(35.4)$ & Positive Adrenaline Challenge & $7(12.5)$ \\
\hline Initial palpitations & $11(30.6)$ & Exercise Tolerance Test & $46(82.1)$ \\
\hline Initial chest pain & $8(22.2)$ & Positive Exercise Tolerance Test & $44(95.7)$ \\
\hline Initial seizure & $16(36.4)$ & EPS & $3(5.4)$ \\
\hline PVC & $40(88.9)$ & Positive EPS & $3(100)$ \\
\hline VT/VF & $51(91.1)$ & Holter Study & $41(73.2)$ \\
\hline VT/VF post-presentation & $17(31.5)$ & Arrhythmia in Holter Study & $31(75.6)$ \\
\hline
\end{tabular}


Table 2. Genetic test results.

\begin{tabular}{|c|c|c|c|c|c|c|c|c|c|}
\hline Gene & Mutation & $\begin{array}{l}\text { Region in } \\
\text { Genome }\end{array}$ & $\begin{array}{l}\text { Coding } \\
\text { Effect }\end{array}$ & Mutation type & $\begin{array}{l}\text { Mutation } \\
\text { Hotspots } \\
\text { for RyR2 }\end{array}$ & Pathogenicity & Predictions & $\begin{array}{l}\text { Novel Mutation } \\
\text { outside China }\end{array}$ & Reference \\
\hline RyR2 & c. $229 \mathrm{C}>\mathrm{T}$ & Exon 3 & P77S & Substitution & Domain I & VUS & VUS & Not applicable & Ge 2017 \\
\hline RyR2 & c. $490 \mathrm{C}>\mathrm{T}$ & Exon 8 & P164S & Substitution & Domain I & VUS & $\begin{array}{c}\text { Likely } \\
\text { Pathogenic }\end{array}$ & No: [58] & Lin 2018 \\
\hline RyR2 & c. $1639 \mathrm{~A}>\mathrm{C}$ & ? Exon 17 & N547H & Substitution & Non-hotspot & VUS & VUS & Not applicable & Ge 2017 \\
\hline RyR2 & c. $2410 \mathrm{C}>\mathrm{T}$ & Exon 22 & L804F & Substitution & Non-hotspot & Likely benign & Benign & RCV000639160.2 & Ge 2017 \\
\hline RyR2 & c.7202G $>A$ & Exon 47 & $\mathrm{R} 2401 \mathrm{H}$ & Substitution & Domain II & $\begin{array}{c}\text { Likely } \\
\text { Pathogenic }\end{array}$ & Pathogenic & No: [41] & Lee 2021 \\
\hline RyR2 & c. $7258 \mathrm{~A}>\mathrm{G}$ & Exon 48 & R2420G & Substitution & Domain II & VUS & VUS & No: [31] & Ge 2017 \\
\hline RyR2 & c. $7420 \mathrm{~A}>\mathrm{G}$ & Exon 49 & R2474G & Substitution & Domain II & VUS & $\begin{array}{c}\text { Likely } \\
\text { Pathogenic }\end{array}$ & No: [28] & Lee 2021 \\
\hline RyR2 & c. $7580 \mathrm{~T}>\mathrm{G}$ & Exon 50 & L2527W & Substitution & Domain II & VUS & VUS & Not applicable & Duan 2018 \\
\hline RyR2 & c. $10046 \mathrm{C}>\mathrm{T}$ & ?Exon 69 & S3349L & Substitution & Non-hotspot & VUS & VUS & No: $[30,42]$ & Lee 2021 \\
\hline RyR2 & c. $11836 \mathrm{G}>\mathrm{A}$ & Exon 88 & G3946S & Substitution & Domain III & Pathogenic & Pathogenic & No: $[43,46]$ & $\begin{array}{l}\text { Ge 2017, } \\
\text { Lee 2021 }\end{array}$ \\
\hline RyR2 & c. $12014 \mathrm{~A}>\mathrm{T}$ & Exon 90 & E4005V & Substitution & Domain III & VUS & VUS & Not applicable & Yang 2021 \\
\hline RyR2 & c. $12272 \mathrm{C}>\mathrm{T}$ & Exon 90 & A4091V & Substitution & Domain III & VUS & VUS & RCV00182811.1 & Yang 2021 \\
\hline RyR2 & c. $12475 \mathrm{C}>\mathrm{A}$ & Exon 90 & Q4159K & Substitution & Domain III & VUS & $\begin{array}{c}\text { Likely } \\
\text { Pathogenic }\end{array}$ & No: [44] & Lee 2021 \\
\hline RyR2 & c.13933T>C & Exon 96 & W4645R & Substitution & Domain IV & VUS & VUS & No: [45] & Ge 2017 \\
\hline RyR2 & c. $14159 \mathrm{~T}>\mathrm{C}$ & ?Exon 97-99 & L4720P & Substitution & Domain IV & VUS & VUS & RCV000182842.2 & Lee 2021 \\
\hline RyR2 & c. $14570 \mathrm{~T}>\mathrm{G}$ & Exon 101 & I4857S & Substitution & Domain IV & VUS & VUS & Not applicable & Ge 2017 \\
\hline RyR2 & c. $14593 \mathrm{C}>\mathrm{A}$ & $\begin{array}{c}\text { ? Exon 101- } \\
102 \\
\end{array}$ & L4865I & Substitution & Domain IV & VUS & VUS & Not applicable & Ge 2017 \\
\hline RyR2 & c. $14834 \mathrm{~A}>\mathrm{G}$ & Exon 105 & Q4945R & Substitution & Domain IV & Likely benign & VUS & Not applicable & Ge 2017 \\
\hline RyR2 & c. $14848 \mathrm{G}>\mathrm{A}$ & Exon 105 & E4950K & Substitution & Domain IV & VUS & $\begin{array}{c}\text { Likely } \\
\text { Pathogenic }\end{array}$ & No: [46] & Lee 2021 \\
\hline RyR2 & c. $14861 C>G$ & Exon 105 & A4954G & Substitution & Domain IV & VUS & VUS & Not applicable & Lee 2021 \\
\hline CASQ2 & c. $97 \mathrm{C}>\mathrm{T}$ & Exon 1 & R33X & Substitution & Not applicable & $\begin{array}{c}\text { Likely Patho- } \\
\text { genic }\end{array}$ & Pathogenic & No: [59] & $\begin{array}{l}\text { Gao 2018, } \\
\text { Li Q 2019 }\end{array}$ \\
\hline CASQ2 & c. $98 \mathrm{G}>\mathrm{A}$ & Exon 1 & R33Q & Substitution & Not applicable & VUS & VUS & No: [60] & Li Q 2019 \\
\hline CASQ2 & c. $244 \bigcirc \mathrm{T}$ & Exon 1 & Q82X & Substitution & Not applicable & VUS & Pathogenic & Not applicable & Ge 2017 \\
\hline CASQ2 & c. $532+1 \mathrm{G}>\mathrm{A}$ & IVS & & $\begin{array}{l}\text { Splice site } \\
\text { mutation }\end{array}$ & Not applicable & VUS & Pathogenic & Not applicable & Li Q 2019 \\
\hline CASQ2 & c. $748 \mathrm{C}>\mathrm{T}$ & Exon 7 & $\mathrm{R} 250 \mathrm{C}$ & Substitution & Not applicable & VUS & VUS & RCV000694480.2 & $\begin{array}{l}\text { Gao 2018, } \\
\text { Li Q 2019 } \\
\end{array}$ \\
\hline
\end{tabular}




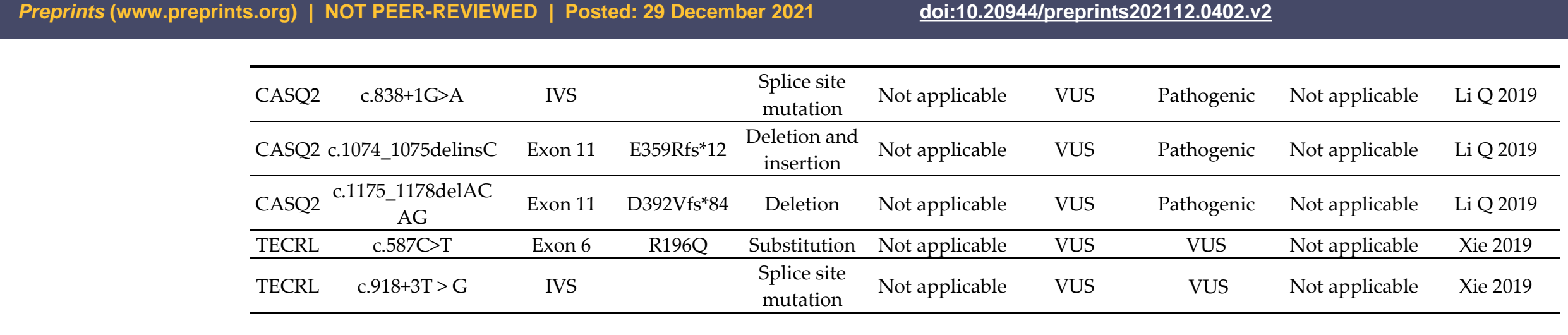

.0402.v2

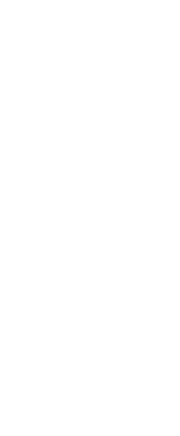

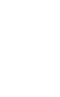

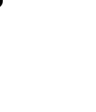

\begin{tabular}{|c|c|c|c|c|c|c|c|c|c|}
\hline CASQ2 & c. $838+1 \mathrm{G}>\mathrm{A}$ & IVS & & $\begin{array}{c}\text { Splice site } \\
\text { mutation }\end{array}$ & Not applicable & VUS & Pathogenic & Not applicable & Li Q 201 \\
\hline CASQ2 & c.1074_1075delinsC & Exon 11 & E359Rfs*12 & $\begin{array}{l}\text { Deletion and } \\
\text { insertion }\end{array}$ & Not applicable & VUS & Pathogenic & Not applicable & Li Q 201 \\
\hline CASQ2 & $\begin{array}{c}\text { c.1175_1178delAC } \\
\text { AG }\end{array}$ & Exon 11 & $\mathrm{D} 392 \mathrm{Vfs}^{*} 84$ & Deletion & Not applicable & VUS & Pathogenic & Not applicable & Li Q 201C \\
\hline TECRL & c. $587 \mathrm{C}>\mathrm{T}$ & Exon 6 & R196Q & Substitution & Not applicable & VUS & VUS & Not applicable & Xie 2019 \\
\hline TECRL & c. $918+3 \mathrm{~T}>\mathrm{G}$ & IVS & & $\begin{array}{c}\text { Splice site } \\
\text { mutation }\end{array}$ & Not applicable & VUS & VUS & Not applicable & Xie 2019 \\
\hline
\end{tabular}


Table 3. Management for CPVT patients in China.

\begin{tabular}{cc}
\hline Treatment & Frequency (\%) \\
\hline$\beta$-blocker & $50(89.2)$ \\
\hline Verapamil & $2(3.6)$ \\
\hline Amiodarone & $4(7.1)$ \\
\hline Flecainide & $8(14.3)$ \\
\hline Propafenone & $1(1.8)$ \\
\hline Sympathectomy & $10(17.9)$ \\
\hline ICD implantation & $7(12.5)$ \\
\hline
\end{tabular}

\section{Discussion}

This is the systematic review and meta-analysis of published cases on CPVT patients from China. There are several novel findings from the present study: 1) RyR2 mutations account for over half of the CPVT cases, 2) 20 RyR variants, seven CASQ2 variants and two TERCL variants were described, 3) $\beta$-blocker are used in $89.2 \%$ of the cases, followed less frequently by flecainide, amiodarone, verapamil and propafenone, and 4) $17.9 \%$ patients underwent cardiac sympathectomy and $12.5 \%$ received ICDs.

Sudden cardiac death is an important clinical problem globally, with congenital and acquired causes [47-50]. Of the congenital cardiac ion channelopathies, CPVT is characterized by exercise-induced bidirectional VT. International registry studies on European and North American patients have reported that there is a malignant arrhythmic phenotype associated with this disease with significant delays between initial presentation and subsequent diagnosis of around six months [17, 51]. By contrast, the epidemiology and characteristics of studies in Asia are limited. In China, cases of CPVT have been limited to small case reports or case series. In this study, we performed a systematic search of the published literature, identifying CPVT cases that have been reported in the following cities: Beijing $(n=22)$ [11, 32-34], Hong Kong $(n=16)$ [25], Guangzhou $(n=8)[35,40]$, Nanjing $(n=6)$ [36], Shanghai $(n=3)[37,38]$ and Sichaun $(n=1)$ [39].

Several studies have examined the occurrence of adverse outcomes in CPVT cohorts, with particular emphasis on syncopal events and SCD [18, 19, 52, 53]. There is existing evidence to suggest that subjects who are initially symptomatic, as similarly shown in our study, as well as those who are younger at diagnosis and are not administered $\beta$-blocker therapy have a significantly higher risk of cardiac events, including syncope, aborted cardiac arrest, and/or sudden cardiac death [18]. Likewise, findings indicate that an initial symptomatic presentation and an absence of $\beta$-blocker administration have also shown to be associated with mortality in CPVT patients [18]. Regarding electrocardiographic parameters, there is a relative paucity in literature assessing their use in risk prediction for VT/VF in the setting of CPVT. However, in the context of SCD as outcome, despite the fact that some reports studying its relationship with ECG variables have demonstrated significant differences in the QRS duration of recorded PVCs between patients who remained alive and those who suffered SCD during follow-up, most other ECG variables, such as those investigated in our study, namely heart rate and QTc interval, failed to demonstrate any notable variations with time [18].

Regarding the genetic basis, this study identified 20 RyR variants. Of these, 12 have been reported outside China: c.490C > T [58], c.2410C >T (RCV000639160.2), c.7202G>A [41], c.7258A >G [31], c.7420A>G [28], c.10046C >T [30, 42], c.11836G>A [43, 46], c.12272C>T (RCV00182811.1), c.12475C $>$ A [44], c.13933T $>$ C [45], c.14159T $>$ C (RCV000182842.2), c.14848G >A [46]. By contrast, c.14861C $>$ G is a novel RyR2 variant that gives rise to the A4954G amino acid change [25]. This mutation affects the cytoplasmic domain of the RyR2, is expected to produce abnormalities in calcium handling, possible diastolic calcium leak and triggered arrhythmogenesis [54]. However, functional studies are 
needed to determine the precise mechanisms by which this structural change can lead to the generation of an electrophysiological substrate. Previous animal studies have reported that the RyR2 mutations can be associated with not only disrupted calcium homeostasis but also reduced conduction velocity [55-57].

CASQ2, in comparison, accounts for a fewer proportion of CPVT cases. In our study, 8 variants were reported. Three have been reported from publications arising from outside China: c.97C $>$ T [59] c.98G >A [60], and c.748C >T (RCV000694480.2), with six novel mutations. The two TERCL variants reported in our study are also novel mutations. Finally, CALM2 has also been implicated in CPVT but our study did not identify mutations in this gene.

\section{Strengths and limitations}

The major strengths of the present study include extraction and integration of data which allows easier interpretation by researchers beyond China and a comprehensive analysis of clinical characteristics, genetic basis and arrhythmic outcomes of CPVT patients from China.

The major limitation of the present study is that data was extracted from case reports or case series. Without a national registry, cases reported may not include all the domains that were assessed in this current study, therefore the data may not reflect the actual picture of CPVT patients from China especially regarding arrhythmic events on followup.

\section{Conclusion}

This is the first systemic review and meta-analysis of CPVT patients from China. Most patients had symptoms on initial presentation, and around a third had VT as the presenting complaint. RyR2 mutation accounts for more than half of the CPVT cases, followed by CASQ2 and TERCL mutations. Some of these mutations have not been hitherto reported outside of China. Most patients received $\beta$-blocker therapy. Around 18\% had sympathectomy and 13\% had ICDs implanted.

Contributor statement: Sharen Lee, Justin Leung, and Gary Tse: study conception, data acquisition, database building, statistical analysis, manuscript drafting, manuscript revision

Jiandong Zhou, Kamalan Jeevaratnam, Ishan Lakhani, Danny Radford, Emma Coakley-Youngs, Levent Pay, Göksel Çinier, Meltem Altinsoy, Elham Mahmoudi, Paweł T. Matusik, George Bazoukis, Sebastian Garcia-Zamora, Shaoying Zeng, Zhiliang Chen, Younlong Xia, Tong Liu: data interpretation, statistical analysis, manuscript revision

Institutional Review Board Statement: Not applicable as the study is a systematic review and metaanalysis of published studies.

Informed Consent Statement: Not applicable.

Data Availability Statement: The data described in this study are available from the published studies.

Conflicts of Interest: The authors declare no conflict of interest

Funding: No funding was secured for this study. 


\section{References}

[1] Rucinski C, Winbo A, Marcondes L, et al. A Population-Based Registry of Patients With Inherited Cardiac Conditions and Resuscitated Cardiac Arrest. J Am Coll Cardiol 2020;75:2698-707.

[2] Li KHC, Lee S, Yin C, et al. Brugada syndrome: A comprehensive review of pathophysiological mechanisms and risk stratification strategies. Int J Cardiol Heart Vasc 2020;26:100468.

[3] Li Z, Chen P, Li C, et al. Genetic arrhythmias complicating patients with dilated cardiomyopathy. Heart Rhythm 2020;17:305-12.

[4] Asatryan B, Schaller A, Seiler J, et al. Usefulness of Genetic Testing in Sudden Cardiac Arrest Survivors With or Without Previous Clinical Evidence of Heart Disease. Am J Cardiol 2019;123:2031-8.

[5] Aiba T. Recent understanding of clinical sequencing and gene-based risk stratification in inherited primary arrhythmia syndrome. J Cardiol 2019;73:335-42.

[6] Munroe PB, Addison S, Abrams DJ, et al. Postmortem Genetic Testing for Cardiac lon Channelopathies in Stillbirths. Circ Genom Precis Med 2018;11:e001817.

[7] Skinner JR, Winbo A, Abrams D, et al. Channelopathies That Lead to Sudden Cardiac Death: Clinical and Genetic Aspects. Heart Lung Circ 2019;28:22-30.

[8] Tse G, Zhou J, Lee S, et al. Incorporating Latent Variables Using Nonnegative Matrix Factorization Improves Risk Stratification in Brugada Syndrome. J Am Heart Assoc 2020:e012714.

[9] Vemireddy LP, Aqeel A, Ying GW, et al. A Rare Case of RYR2 Mutation Causing Sudden Cardiac Arrest Due to Catecholaminergic Polymorphic Ventricular Tachycardia. Cureus 2021;13:e13417.

[10] Ng K, Titus EW, Lieve KV, et al. An International Multicenter Evaluation of Inheritance Patterns, Arrhythmic Risks, and Underlying Mechanisms of CASQ2-Catecholaminergic Polymorphic Ventricular Tachycardia. Circulation 2020;142:932-47.

[11] Li Q, Guo R, Gao L, et al. CASQ2 variants in Chinese children with catecholaminergic polymorphic ventricular tachycardia. Mol Genet Genomic Med 2019;7:e949.

[12] Crotti L, Spazzolini C, Tester DJ, et al. Calmodulin mutations and life-threatening cardiac arrhythmias: insights from the International Calmodulinopathy Registry. Eur Heart J 2019;40:2964-75.

[13] Badone B, Ronchi C, Kotta MC, et al. Calmodulinopathy: Functional Effects of CALM Mutations and Their Relationship With Clinical Phenotypes. Front Cardiovasc Med 2018;5:176.

[14] Jimenez-Jaimez J, Palomino Doza J, Ortega A, et al. Calmodulin 2 Mutation N98S Is Associated with Unexplained Cardiac Arrest in Infants Due to Low Clinical Penetrance Electrical Disorders. PLoS One 2016;11:e0153851.

[15] Behere SP, Weindling SN. Catecholaminergic polymorphic ventricular tachycardia: An exciting new era. Ann Pediatr Cardiol 2016;9:137-46.

[16] Roston TM, Haji-Ghassemi O, LaPage MJ, et al. Catecholaminergic polymorphic ventricular tachycardia patients with multiple genetic variants in the PACES CPVT Registry. PLoS One 2018;13:e0205925.

[17] Roston TM, Yuchi Z, Kannankeril PJ, et al. The clinical and genetic spectrum of catecholaminergic polymorphic ventricular tachycardia: findings from an international multicentre registry. Europace 2018;20:541-7.

[18] Hayashi M, Denjoy I, Extramiana F, et al. Incidence and risk factors of arrhythmic events in catecholaminergic polymorphic ventricular tachycardia. Circulation 2009;119:2426-34.

[19] Leenhardt A, Lucet V, Denjoy I, et al. Catecholaminergic polymorphic ventricular tachycardia in children. A 7-year follow-up of 21 patients. Circulation 1995;91:1512-9.

[20] Coumel P. Catecholaminergic-induced severe ventricular arrhythmias with Adams-Stokes syndrome in children : report of four cases. Br Heart J 1978;40:28-37.

[21] Sumitomo N. Current topics in catecholaminergic polymorphic ventricular tachycardia. J Arrhythm 2016;32:34451.

[22] Kawamura M, Ohno S, Naiki N, et al. Genetic background of catecholaminergic polymorphic ventricular tachycardia in Japan. Circ J 2013;77:1705-13.

[23] Sumitomo N, Harada K, Nagashima M, et al. Catecholaminergic polymorphic ventricular tachycardia: electrocardiographic characteristics and optimal therapeutic strategies to prevent sudden death. Heart 2003;89:6670.

[24] Jiang $\mathrm{H}$, Li XM, Ge HY, et al. Investigation of Catecholaminergic Polymorphic Ventricular Tachycardia Children in China: Clinical Characteristics, Delay to Diagnosis, and Misdiagnosis. Chin Med J (Engl) 2018;131:2864-5. 
[25] Lee S, Zhou J, Jeevaratnam K, et al. Arrhythmic Outcomes in Catecholaminergic Polymorphic Ventricular Tachycardia. medRxiv 2021:2021.01.04.21249214.

[26] Mak CM, Chen SP, Mok NS, et al. Genetic basis of channelopathies and cardiomyopathies in Hong Kong Chinese patients: a 10-year regional laboratory experience. Hong Kong Med J 2018;24:340-9.

[27] Priori SG, Wilde AA, Horie M, et al. HRS/EHRA/APHRS expert consensus statement on the diagnosis and management of patients with inherited primary arrhythmia syndromes: document endorsed by HRS, EHRA, and APHRS in May 2013 and by ACCF, AHA, PACES, and AEPC in June 2013. Heart Rhythm 2013;10:1932-63.

[28] Ozawa J, Ohno S, Fujii Y, et al. Differential Diagnosis Between Catecholaminergic Polymorphic Ventricular Tachycardia and Long QT Syndrome Type 1- Modified Schwartz Score. Circ J 2018;82:2269-76.

[29] Landstrom AP, Dailey-Schwartz AL, Rosenfeld JA, et al. Interpreting Incidentally Identified Variants in Genes Associated With Catecholaminergic Polymorphic Ventricular Tachycardia in a Large Cohort of Clinical Whole-Exome Genetic Test Referrals. Circ Arrhythm Electrophysiol 2017;10.

[30] Seidelmann SB, Smith E, Subrahmanyan L, et al. Application of Whole Exome Sequencing in the Clinical Diagnosis and Management of Inherited Cardiovascular Diseases in Adults. Circ Cardiovasc Genet 2017;10.

[31] Medeiros-Domingo A, Bhuiyan ZA, Tester DJ, et al. The RYR2-encoded ryanodine receptor/calcium release channel in patients diagnosed previously with either catecholaminergic polymorphic ventricular tachycardia or genotype negative, exercise-induced long QT syndrome: a comprehensive open reading frame mutational analysis. J Am Coll Cardiol 2009;54:2065-74.

[32] Ge HY, Li XM, Jiang H, et al. [Clinical challenges in the management of catecholaminergic polymorphic ventricular tachycardia in children]. Zhonghua Er Ke Za Zhi 2017;55:926-31.

[33] Gao L, Cui L, Zheng L, et al. A novel variant of the CASQ2 gene in a Chinese family with catecholaminergic polymorphic ventricular tachycardia. Cardiol J 2018;25:756-8.

[34] Yang J, Li K, Chen DH, et al. [Treatment efficiency evaluation of left cardiac sympathetic denervation for patients with inherited arrhythmia by exercise-stress test]. Zhonghua Xin Xue Guan Bing Za Zhi 2021;49:796-801.

[35] Li ZL, Zeng SY, Liang DP, et al. [Analysis of 30 cases of inherited cardiac arrhythmia syndrome in children]. Zhonghua Er Ke Za Zhi 2019;57:700-4.

[36] Zhao DS, Shen JH, Lu JP, et al. [Clinical features of six patients with catecholaminergic polymorphic ventricular tachycardia]. Zhonghua Xin Xue Guan Bing Za Zhi 2012;40:844-8.

[37] Chen YW, Ji W, Zhu DQ, et al. [Efficacy and safety of implantable cardioverter-defibrillator implantation in pediatric tachycardia cases]. Zhonghua Er Ke Za Zhi 2020;58:905-9.

[38] Xie L, Hou C, Jiang X, et al. A compound heterozygosity of Tecrl gene confirmed in a catecholaminergic polymorphic ventricular tachycardia family. Eur J Med Genet 2019;62:103631.

[39] Duan H, Lu Y, Yan S, et al. A delayed diagnosis of catecholaminergic polymorphic ventricular tachycardia with a mutant of RYR2 at c.7580T>G for 6 years in a 9-year-old child. Medicine (Baltimore) 2018;97:e0368.

[40] Lin Y, He S, Liao Z, et al. Whole exome sequencing identified a pathogenic mutation in RYR2 in a Chinese family with unexplained sudden death. J Electrocardiol 2018;51:309-15.

[41] Aizawa Y, Ueda K, Komura S, et al. A novel mutation in FKBP12.6 binding region of the human cardiac ryanodine receptor gene $(\mathrm{R} 2401 \mathrm{H})$ in a Japanese patient with catecholaminergic polymorphic ventricular tachycardia. Int J Cardiol 2005;99:343-5.

[42] Christiansen SL, Hertz CL, Ferrero-Miliani L, et al. Genetic investigation of 100 heart genes in sudden unexplained death victims in a forensic setting. Eur J Hum Genet 2016;24:1797-802.

[43] Gallegos-Cortez A, Alonso-Ortiz N, Antunez-Arguellez E, et al. Catecholaminergic polymorphic ventricular tachycardia due to de novo RyR2 mutation: recreational cycling as a trigger of lethal arrhythmias. Arch Med Sci 2020;16:466-70.

[44] Kawata H, Ohno S, Aiba T, et al. Catecholaminergic Polymorphic Ventricular Tachycardia (CPVT) Associated With Ryanodine Receptor (RyR2) Gene Mutations- Long-Term Prognosis After Initiation of Medical Treatment. Circ J 2016;80:1907-15.

[45] Beery TA, Shah MJ, Benson DW. Genetic characterization of familial CPVT after 30 years. Biol Res Nurs 2009;11:6672.

[46] Priori SG, Napolitano C, Memmi M, et al. Clinical and molecular characterization of patients with catecholaminergic polymorphic ventricular tachycardia. Circulation 2002;106:69-74.

[47] Pappone C, Micaglio E, Locati ET, et al. The omics of channelopathies and cardiomyopathies: what we know and how they are useful. Eur Heart J Suppl 2020;22:L105-L9. 
[48] Pappone C, Ciconte G, Micaglio E, et al. Common modulators of Brugada syndrome phenotype do not affect SCN5A prognostic value. Eur Heart J 2021;42:1273-4.

[49] Micaglio E, Monasky MM, Bernardini A, et al. Clinical Considerations for a Family with Dilated Cardiomyopathy, Sudden Cardiac Death, and a Novel TTN Frameshift Mutation. Int J Mol Sci 2021;22.

[50] Monasky MM, Micaglio E, Ciconte G, et al. Brugada Syndrome: Oligogenic or Mendelian Disease? Int J Mol Sci 2020;21.

[51] Roston TM, Vinocur JM, Maginot KR, et al. Catecholaminergic polymorphic ventricular tachycardia in children: analysis of therapeutic strategies and outcomes from an international multicenter registry. Circ Arrhythm Electrophysiol 2015;8:633-42.

[52] Postma AV, Denjoy I, Kamblock J, et al. Catecholaminergic polymorphic ventricular tachycardia: RYR2 mutations, bradycardia, and follow up of the patients. J Med Genet 2005;42:863-70.

[53] Bauce B, Rampazzo A, Basso C, et al. Screening for ryanodine receptor type 2 mutations in families with effortinduced polymorphic ventricular arrhythmias and sudden death: early diagnosis of asymptomatic carriers. J Am Coll Cardiol 2002;40:341-9.

[54] Tse G. Mechanisms of cardiac arrhythmias. J Arrhythm 2016;32:75-81.

[55] Saadeh K, Achercouk Z, Fazmin IT, et al. Protein expression profiles in murine ventricles modeling catecholaminergic polymorphic ventricular tachycardia: effects of genotype and sex. Ann N Y Acad Sci 2020;1478:6374.

[56] Ning F, Luo L, Ahmad S, et al. The RyR2-P2328S mutation downregulates Nav1.5 producing arrhythmic substrate in murine ventricles. Pflugers Arch 2016;468:655-65.

[57] Zhang $\mathrm{Y}, \mathrm{Wu}$ J, Jeevaratnam $\mathrm{K}$, et al. Conduction slowing contributes to spontaneous ventricular arrhythmias in intrinsically active murine RyR2-P2328S hearts. J Cardiovasc Electrophysiol 2013;24:210-8.

[58] Choi G, Kopplin LJ, Tester DJ, et al. Spectrum and frequency of cardiac channel defects in swimming-triggered arrhythmia syndromes. Circulation 2004;110:2119-24.

[59] Postma AV, Denjoy I, Hoorntje TM, et al. Absence of calsequestrin 2 causes severe forms of catecholaminergic polymorphic ventricular tachycardia. Circ Res 2002;91:e21-6.

[60] Terentyev D, Nori A, Santoro M, et al. Abnormal interactions of calsequestrin with the ryanodine receptor calcium release channel complex linked to exercise-induced sudden cardiac death. Circ Res 2006;98:1151-8. 